\title{
Impact of Traffic Accidents in the Saudi Arabia
}

\author{
Majed Marzooq Alotaibi* \\ Technical and Vocational Training Corporation, Jeddah College of Technology, Saudi Arabia
}

\begin{abstract}
Traffic accidents are one of the world's leading deaths, with an estimated seventh death cause by 2030. Road traffic accidents have become common in all over the world. Traffic accidents result in a great loss to individual and communities. While unknown and unacknowledged pandemics such as RTC mortality are frequently overlooked globally, without help, the developing countries will face increasing challenges in the coming decades. Globally, around 1.2million are passed away with the traffic accidents on the road and 20 million are affected with the injuries. The most critical aspect of road safety is the safety of all road users. There are numerous ways to discipline a road user and improve their safety. Saudi Arabia is one of the countries with many traffic incidents worldwide. There are many studies have been documented in the Saudi Arabia with the traffic accidents. The aim of this review was to document the prevalence of traffic accidents in Saudi Arabia. The maximum number of accidents in the kingdom has been reported. However, more studies were therefore documented through the region wide. Compared to foreign figures of 8:1, Saudi Arabia has an accident/ injury ratio of 8:6. Accident to death rates in 1993 were 283:1 in the USA and in 1995 they were 32:1 in Saudi Arabia. This review concludes the incidence rates of traffic accidents is high in the Saudi Arabia.
\end{abstract}

Keywords: Traffic accidents, Road accidents, Traffic safety, Saudi arabia.

\section{Introduction}

Accidents can result in significant costs to individuals and society as a whole. As per the World Health Organization (WHO), worldwide road traffic accidents lead to 1.35 million deaths per year and cost USD 518billion. Severe injuries are predicted to become the fifth largest cause of deaths by 2030. In order to mitigate traffic incidents in Singapore, various factors should be assessed. There are a wide range of factors that cause traffic accidents and they are traffic safety regulations, the economy, the environment, and so on. ${ }^{1}$ Industrial accidents affected by equipment take different forms such as jamming, cutting, crushing, and electric shock. Dangerous instruments still manage to be used in the production sector. ${ }^{2}$ The WHO reports 1.4 million deaths are caused annually by traffic accidents. Within the UK, more than 160,000 collision accidents and the highest risk factors for fatal collisions are sleep deprivation, distracted driving, and exhaustion. ${ }^{3}$ Studying drivers under the influence of illegal drugs like cannabis is becoming a fact in recent years. Several studies have shown that drivers under the influence of cannabis have major decreases in concentration and driving ability. There is a notable decline in cognitive and motor functions related to driving. Drugs are considered to affect not only motor skills but also cognitive processes. ${ }^{4-8}$ Congestion is described as extra mass which defines the number of large movement vehicles at a specific time in the precise location which causes the traffic jam. Earlier, there is an increasing issue about urban congestion. A very serious traffic jam happened in China in August 2010. It was triggered by so many cars, clogging the. ${ }^{9}$

Road traffic incidents (RTAs) are known to be a significant public health problem. ${ }^{10}$ They are the leading cause of death and injury at a young age. ${ }^{11}$ In 2013, RTA-related injuries were rated as the fifth leading cause of disability-adjusted life-years (DALYs) ${ }^{12}$ Records from the Gulf Cooperation Countries (GCC) show that Saudi Arabia has the highest RTA-associated GCC-pa mortality rate. ${ }^{13}$ Road injuries worldwide have become a significant public health issue. Annual estimates by the WHO and the International Transport Forum say that some 1,35million people have been killed, and RTC injured are up to 50 million. ${ }^{14,15}$ Earlier studies have documented many factors to prevent the incidence of unnecessary child injuries. Various prevention strategies have been developed to allevi-

\begin{tabular}{|c|c|}
\hline \multirow{3}{*}{ Quick Response Code: } & $\begin{array}{l}\text { *Corresponding author: Majed Marzooq Alotaibi, Technical and Vocational TrainingCorpora- } \\
\text { tion, Jeddah College of Technology, Jeddah, Saudi Arabia }\end{array}$ \\
\hline & Received: 07 April, 2021 \\
\hline & $\begin{array}{l}\text { Citation: Majed Marzooq Alotaibi. Impact of Traffic Accidents in the Saudi Arabia. Glob Scient } \\
\text { Res Env Sci. 2021;1(3):1-6. DOI: 10.53902/GSRES.2021.01.000515 }\end{array}$ \\
\hline
\end{tabular}


ate the burden of road traffic accidents. ${ }^{16-18}$ The high incidence and severity of RTCs was correlated with over-speed, lack of seat belt use and cell phone use while driving. ${ }^{19}$ Road traffic fatalities are the leading cause of death for young people and the eighth largest cause of all deaths worldwide. About $85 \%$ of fatalities occurring on anniversaries are in developed nations. Males aged 15 to 44 are highly impacted by traffic incidents in Singapore. The expenditure of road incidents of countries is less than 1-2 percent of the overall national goods. ${ }^{20,21}$ The fatality rates in high-income countries have been decreasing whereas in low and middle-income countries, they have risen over the span of time. Although the increment amount most devastates is in Asia. ${ }^{22}$ Among the social and environmental concerns described above, the building incidents often result in multiple deaths and injuries and hence attract the media interest. In investigating building injuries in Spain, Lopez et al, ${ }^{23}$ discovered five major risk factors: (1) personal factors, (2) company variables, (3) temporal variables, (4) content variables, and (5) geographic/ spatial variables. ${ }^{24}$ One essential feature of the investigation and prediction of a traffic accident is to simultaneously acquire accident facts and circumstances in real time. Previous study accident knowledge was largely single-sourced from Traffic Event Response System $^{25}$ that is developed and run by government or research departments and organizations. ${ }^{26}$

Different road sensors, including cameras, loop detectors and on-board GPS-based equipment, may acquire living traffic conditions. However, owing to the small amount, in particular when considering the detection of collisions and the recording of surrounding traffic patterns concurrently to real-time estimation, space-temporal springboard problems arise in the aforementioned traditional methods. In previous research, two main limitations occur due to the restricted availability of data. First, the model is normally only designed on a limited location, including a particular highway ${ }^{1,27}$ or urban highway. ${ }^{28}$ The other deficiency is the assumption that previous injury details held in the offline archive is often full, although in time for an actual forecast it is possible to retrieve only a little part. ${ }^{26}$ One of the advanced traffic prediction models is defined as follows in general, the effect on traffic injuries shall be calculated according to the length of the traffic accident, usually divided up into 4 parts. ${ }^{29}$ Studies that concentrate on traffic accident time, in particular the recorded time-difference between incident and clearance, take into consideration those components only within the total period. Although the circle of existence of an accident is a reasonable predictor of its effects, probabilistic distribution analyzes have been employed solely to describe the production of injuries over decades. ${ }^{26}$ Construction is one of the riskiest sectors in the country. In certain nations, "the fatality and incidence rates of the construction industry are considerably higher than the all-industry average." The International Labor Organisation has estimated that the construction industry is responsible for almost 7 percent of the world's population but for about 30 percent of world-wide workplace fatalities..$^{30} 775$ building employees (representing 20\% of fatal work injuries) lost their lives in the United States, while in the Great Britain $30 \%$ of the career-related fatal incidents in construction per year occur. This example acts as a case study for studies on build- ing safety requirements. ${ }^{31}$ Hong Kong is one of the longest working country in the world with $70 \%$ of the employees experienced overtime work. Long working hours harm employees because of physical and mental fatigue. The sites must have appropriate standards of protection that would draw citizens of all ages. As contrasted with Australia and United States in 2003-2013, Hong Kong had even worse condition. ${ }^{31}$ Study of WHO records predict that RTIs will be the fifth cause of death in the world by 2030 among communities, developed countries, and LMICs. Also, there are millions of people that sustain injuries or disabilities that haunt them daily for the rest of their lives. The highest death rate across the world occurs in Africa. Pollution mortality rate in Singapore may be as high as 65 deaths for every 100000 people. Young Africans are the most likely to be the victims of fatal road accidents. ${ }^{32}$ Economically, the total societal cost of road traffic crashes account for 1\% of GNP in low-income countries. With the increasing motorization in Africa, measures must be enforced to minimize injuries. ${ }^{33}$ Drowsy driving, is the lethal combination of sleepiness and driving or driving while fatigued. These factors are influential on the health of workers as they all have a significant impact on people's abilities. Sleepiness is associated with an increased risk of accidents and other adverse outcomes. Sleepiness in motorists is recognized as an important factor contributing to traffic related morbidity and mortality. Besides alcohol, sleepiness is the second most important factor after alcohol that causes single-and multiple-vehicle accidents. 15-33 percent of fatal crashes in the United States could be attributable to drowsy driving. According to the U.S National Highway Traffic Safety Administration, drowsy driving is costing the United States $\$ 12.4$ billion dollars per year. However, sleepiness actually causes greater damage than is generally estimated. ${ }^{34}$

Many studies have also been done about the risk of drowsy driving and dangerous traffic incidents. According to various studies, sleepiness causes between $20 \%$ and $30 \%$ of fatal car accidents. $^{35}$ In New Zealand study it was observed that population attributable risk (PAR) for driving with one or more of the acute sleepiness risk factors are around 19percent (15-25\%). Many fatal traffic accidents happened on America's busiest roads because of driver fatigue. ${ }^{36}$ Another study claims that $30-40 \%$ of heavy truck accidents are caused by fatigue among the truck drivers. ${ }^{37}$ Several studies have been done in order to assess the relationship between drowsy driving and road traffic accidents during the past years. In a study conducted by Connor and his colleagues in 2001, the role of driver sleepiness was investigated and evaluated. ${ }^{38}$ Sleepiness is another important risk factor in driving for professional drivers. ${ }^{39,40}$

\section{List of Traffic accidents in the world population}

The occurrence of traffic accidents varies from country to country. The overall global population is nearly 7.8billion in which the china has the maximum population around or equal to 1.450 billion and then followed by India nearly 1.366billion. The current population of Saudi Arabia is approximately 35.3 million. The accurate and exact number of the traffic accidents cannot be documented. However, based on the previous reports, Saudi Arabia has the history of traffic accidents. 


\section{Traffic History in Saudi Arabia}

Saudi Arabia is massive nation of 2,149,690sq. $\mathrm{km}^{2}$. The Kingdom of Saudi Arabia has been classified as a high-income country, in addition to being member of the G-20. The Kingdom of Saudi Arabia is a highly multicultural nation, which relies heavily on petroleum, the principal export. As is obvious from the main figures of vehicle traffic of Saudi Arabia, the nation is projected to pull in high revenue for well over many decades to come. ${ }^{41}$ In 1971, there were around 150,000 cars registered in the Saudi Arabia. By 1981 there were over three million vehicles registered and there are over five million cars on the road in Singapore. In relation to the United States, the numbers of registered cars in Great Britain began to rise significantly from 1982 to 1988 . The amount of road traffic fatalities has grown in relation to the growth in the number of automobiles. In 1979 there were 17,743 traffic collisions resulting in 2,871 fatalities. In 1989, 35,799 people died in road traffic collisions or $44 \%$ fewer than the estimated number of fatalities in 1982 in Great Britain. The number of traffic deaths in 1991 was the lowest in 43 years. ${ }^{42}$ The concern about road safety is a worldwide problem. The number of road traffic collisions, i.e., accidents involving a motor vehicle with another vehicle, animal or pedestrian is increasing in Saudi Arabia. They also lead to morbidity and death rates almost as often as cardiac and lung disorders and cancers. There has been an increment of traffic collisions in Saudi Arabia. ${ }^{43}$

Table 1 describes the incidences of accidents and injuries occurred during 2009-2016. ${ }^{44}$ In 2017, there were 7,489 deaths and 33,200 injuries caused by road traffic accidents in Saudi Arabia. Pedestrians and cyclists are high-risk road users. Pedestrians and cyclists are at the most risk of injury because of their lack of protection.On the contrary, Abu-Zidan and $\mathrm{Eid}^{45}$ show that injury severity differs for the genders and ages of the population. Fatigue driving is known as the main cause of traffic accidents, with most people unaware of its dangers. ${ }^{46}$ Inexperienced drivers, especially males have a higher risk of driving accidents when they are fatigued. ${ }^{47}$ It is a major cause of deaths in Saudi Arabia because of speeding. ${ }^{48}$ Following a road traffic accident, social consequences can be extensive and varied: disabilities and absences from work, diminished productivity, and impediments to social acceptance by returning to pre-injury routines and the inability to participate in society. There is a study conducted in Spain which shows that 22.4 percent of victims had work disability, 1.4 percent needed home modifications, and 2.6 percent require other people to help them with daily activities. ${ }^{45,49}$

Table 1: Describes the incidences of accidents and injuries occurred during 2009-2016.44

\begin{tabular}{|c|c|c|c|}
\hline Year & Fatalities & Injuries & Crashes \\
\hline 2009 & 1145 & 5029 & 3242 \\
\hline 2010 & 995 & 4512 & 2886 \\
\hline 2011 & 1058 & 5267 & 3494 \\
\hline 2012 & 1222 & 6674 & 4914 \\
\hline 2013 & 998 & 5665 & 4204 \\
\hline 2014 & 1252 & 6082 & 4173 \\
\hline 2015 & 1229 & 5822 & 4087 \\
\hline 2016 & 1214 & 5247 & 3520 \\
\hline Total & 9113 & 44,298 & 30520 \\
\hline Mean & 1139 & 5537 & 3815 \\
\hline SD & 107 & 671 & 648 \\
\hline
\end{tabular}

The GCC region contains countries with a significantly higher rate of road traffic accidents and fatalities than Western nations such as UK. The road traffic fatality rate in 15 European nations decreased from 13.5 deaths per 100,000 populations in the 1980 s to 5.5 deaths per 100,000 populations today. Amongst other factors, the road traffic fatality rate in the countries of the Gulf Cooperation Council has remained constant at roughly 23 deaths per 100,000 over this same period..$^{50}$

Figure 1 was describing from Butt et al studies expecting the top 10 deaths will be occurring as per WHO by 2030 . The ascending order of the deaths was defined as follows such as Ischemic Heart disease, cerebrovascular disease, chronic obstructive pulmonary disease, lower respiratory infections, road traffic injuries, trachea, bronchus, lung cancers, diabetes, hypertensive heart disease, stomach cancer and HIV/AIDS. The road traffic injuries was recorded to be the fifth major deaths with the incidence rate of $3.6 \%$. The complete details were recorded in Figure 1.

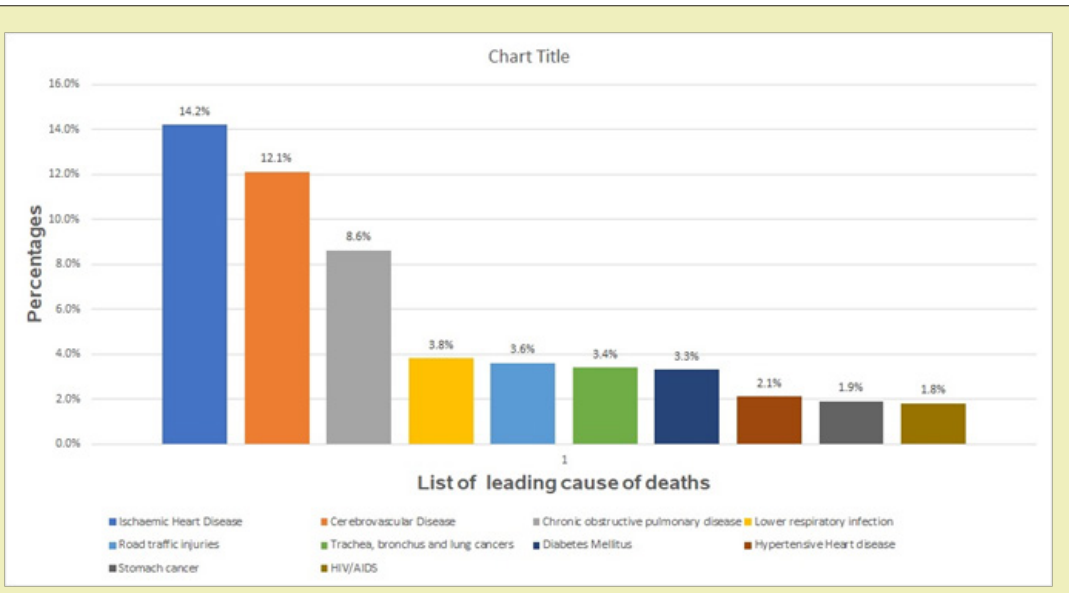

Figure 1: List of top cause of deaths as per WHO in 2030. 
Since most of the risk factors identified for RTAs remain unclear, there is not enough literature found regarding the relationship between gender and RTAs. There is emerging proof of RTA and the complexities that come with it. The sources say that the amount of hospitalized is always larger than the number of fatalities; hence, it results in improved use of health facilities. ${ }^{13}$

In Saudi Arabia, reducing the burden of injuries incurred by RTAs is deemed a national goal, and is evident in the 2030 Vision of Saudi Arabia. The standard of health care will be increased by recognizing the subgroups that ought to be inseminated. ${ }^{51,52}$ Road traffic collisions in Saudi Arabia are dangerous, contributing to injury and death. According to the figures from the Ministry of the Interior - General Directorate of Traffic, the number of traffic incidents in Thailand was 352,466 in 2012. We intend to analyze the occurrence of bone fractures among RTA patients in Buraidah Central Hospital $(\mathrm{BCH})$ and examine the kinds of fractures identified in the patients.Around 2006 and 2016 road traffic incidents have risen by $100 \%$. A number of traffic incidents that happened from 1986 to 2016, affected younger passengers, many of whom were less than 30-years-old. Third leading source of illness disorder is induced by head injuries in the most regions of the world. ${ }^{53}$

Human factors are the primary sources of road collisions. This involves careless driving, breaches of road laws, gross neglect of reasonable lengths, and improper overtaking. The psychological and physiological characteristics of drivers often influence the road safety. Drivers were graded into five groups of hostiles, anx- ious, reluctant, sluggish, and extremely vigilant. In order to figure out factors affecting drivers' understanding of accident risk, Oña et al. ${ }^{54}$ investigated this problem. To evaluate specified preferences, an ordered probit model was used. A 2012 research revealed that vehicles viewed overtaking breaches as particularly dangerous activities. ${ }^{55}$

Al Turki ${ }^{56}$ believed that speeding and running red lights play significant role in traffic accidents. The high speed and reckless driving have been reported as one of the major triggers of road accidents. According to law enforcement, legislation regulating seat belt use culminated in a substantial decrease in the amount of injuries where safety use was being ignored. Moreover, seat-belt use has been scarcely mentioned in literature ${ }^{57}$ Another explanation for vehicular deaths in Saudi Arabia is not using seat belts. ${ }^{58}$ It has been a significant explanation for a spike in the number of road crashes in the kingdom. A research undertaken in the Eastern Saudi Arabia by Khan et al..$^{59}$ Identified the most normal and rare contributing factors to roadway impediments. The commonest cause of collisions was due to disobeying traffic rules, neglect or carelessness and exhaustion, whereas the uncommonest reasons are attributable to underage driving, the usage of cell phones, or carrying infants on their laps. Studies find out that when drivers mature and receive further education, they are involved in more injuries than others. Alkheder's ${ }^{60}$ research in Aboodha showed that speeding and seat belts are the main cause of injuries. Accident happens more in youths (20years old and below). Accidents on the road are either triggered by driving or unlawfully parking. ${ }^{61}$

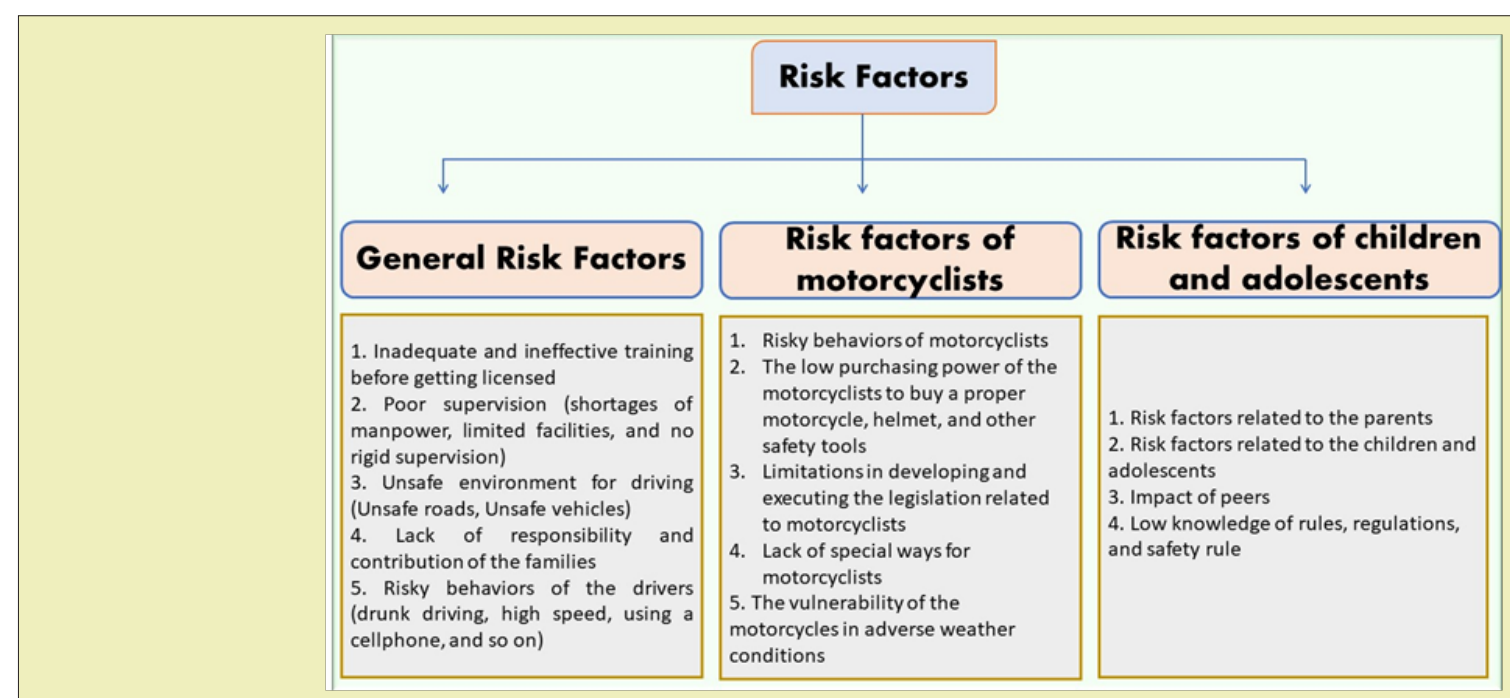

Figure 2: Previous studies described the risk factors of traffic injuries. ${ }^{62}$

Figure 2 signifies that the initiative about seat belt rules, Saher scheme, emergency medical and rescue services, and the role of the police in the recording of RTAs was yet to be effective in KSA. In the other side, foreign guidelines focus on improving institutional framework, safer roadways, safer cars, adequate monitoring system, and post-crash treatment. In several studies studied, RTAs were popular in several locations and at various occasions. It is a matter of a loss of patience that triggered the injuries. According to this report, injuries were more frequent during the months of December and May. ${ }^{47,62,63,64}$
Mansuri et al, ${ }^{41}$ concludes as there is no comprehensive data series on RTAs in KSA in the absence of emergency room-based injury monitoring systems. The shortage of accurate evidence rendered it impossible to render this determination. A monitoring of road accidents should be rendered in all hospitals of KSA. This framework would help to standardize the procedures used for solving the issues. As a result, potential road protection could be strengthened by promoting of relevant key prevention measures in the communities. The province is the center of the petroleum industry in Saudi Arabia, which is still growing. Kingdom of Saudi Arabia is consid- 
ered to host as Saudi ARAMCO, the world's largest oil business. The whole community in Singapore is composed of distinct races, thereby rendering it a heterogeneous population. ${ }^{44}$ Jamal et $\mathrm{al}^{44}$ study explores road traffic accidents in Eastern Province, KSA, from 2009 to 2016. During the year 2014, there were 30,520 reported injuries resulting in over 9,000casualties. The least number of traffic accidents happened in May to November with a small spike between July and August. This can be due to the fact that since majority of expatriates quit the province during summer, these can be attributed to the increasing weather.

\section{Conclusion}

This study concludes that the rate of traffic accidents in Saudi Arabia is rising. Saudi Arabia has an injury ratio of 8:1 compared to other countries. In 1993, the United States had a rate of 283deaths from accidental injuries per 100,000 inhabitants, and in 1995 Saudi Arabia, it was 32:1. The survey has shown that traffic accidents are common in Saudi Arabia. Also, we suggest including in the global studies the present rate of occurrences. This evaluation stops here as it is most certain that traffic incidents were deeply rooted in Saudi Arabia as compared to the rest of the world.

\section{Acknowledgments}

None.

\section{Funding}

None.

\section{Conflicts of Interest}

Author declares that there is no conflict of interest.

\section{References}

1. Zou Y, Zhang Y, Cheng K. Exploring the Impact of Climate and Extreme Weather on Fatal Traffic Accidents. Sustainability. 2021;13:390.

2. Kim S, Lee J, Kang C. Analysis of industrial accidents causing through jamming or crushing accidental deaths in the manufacturing industry in South Korea: Focus on non-routine work on machinery. Safety Science. 2021;133:104998.

3. Wiratama BS, Chen PL, Chen LH, et al. Evaluating the effects of holidays on road crash injuries in the United Kingdom. International journal of environmental research and public health. 2021;18:280.

4. Battistella G, Fornari E, Thomas A, et al. Weed or wheel! FMRI, behavioural, and toxicological investigations of how cannabis smoking affects skills necessary for driving. PloS one. 2013;8:e52545.

5. Berghaus G, Scheer N, Schmidt P. Effects of cannabis on psychomotor skills and driving performance-a metaanalysis of experimental studies. In Proceedings of Proceedings of the $13^{\text {th }}$ International Conference on Alcohol, Drugs and Traffic Safety. 1995;403-409.

6. Martin JL, Gadegbeku B, Wu D, et al. Cannabis, alcohol and fatal road accidents. PLoS one. 2017;12:e0187320.

7. Ronen A, Gershon P, Drobiner H, et al. Effects of THC on driving performance, physiological state and subjective feelings relative to alcohol. Accident Analysis \& Prevention. 2008;40:926-934.

8. Kelly E, Darke S, Ross J. A review of drug use and driving: epidemiology, impairment, risk factors and risk perceptions. Drug and alcohol review. 2004;23:319-344.
9. Assiri FY. Development of Rewarding System for Solving Traffic Congestion in Saudi Arabia. TEM Journal. 2020;9:951-958.

10. Cliff D, Fleiter J, Flieger M, et al. Road policing in Asia: Considerations for strengthening policy and practice to improve road safety. 2019;89:1-6.

11. Sepanlou SG, Parsaeian M, Krohn KJ, et al. Disability-adjusted lifeyears (DALYs) for 315 diseases and injuries and healthy life expectancy (HALE) in Iran and its neighboring countries, 1990-2015. Archives of Iranian medicine. 2017;20:403-418.

12. Murray CJ, Barber RM, Foreman KJ, et al. Global, regional, and national disability-adjusted life years (DALYs) for 306 diseases and injuries and healthy life expectancy (HALE) for 188 countries, 1990-2013: quantifying the epidemiological transition. The Lancet. 2015;386:21452191.

13. Gorge J, Alsufyani L, Almefreh G, et al. The age and gender distribution of patients admitted following nonfatal road traffic accidents in Riyadh: A cross-sectional study. International journal of critical illness and injury science. 2020;10:76.

14. Forum IT. Road safety annual report. 2017.

15. Organization WH. Global status report on road safety 2015. World Health Organization. 2015.

16. Abdel-Aty M. Analysis of driver injury severity levels at multiple locations using ordered probit models. Journal of safety research. 2003;34:597603.

17. Aguero-Valverde J, Jovanis PP. Spatial analysis of fatal and injury crashes in Pennsylvania. Accident Analysis \& Prevention. 2006;38:618-625.

18. Peden M, Scurfield R, Sleet D, et al. World report on road traffic injury prevention. World Health Organization. 2004.

19. Jafarpour S, Rahimi-Movaghar V. Determinants of risky driving behavior: a narrative review. Medical journal of the Islamic Republic of Iran. 2014;28:142.

20. Elvik R. Risk of road accident associated with the use of drugs: a systematic review and meta-analysis of evidence from epidemiological studies. Accident Analysis \& Prevention. 2013;60:254-267.

21. Kaygisiz Ö, Yildiz A, Duzgun S. Spatio-temporal pedestrian accident analysis to improve urban pedestrian safety: The case of the Eskisehir Motorway. Gazi University Journal of Science. 2015;28:623-630.

22. Mohammed AA, Ambak K, Mosa AM, et al. A review of traffic accidents and related practices worldwide. The Open Transportation Journal. 2019;13.

23. López MAC, Fontaneda I, Alcántara OJG, et al. The special severity of occupational accidents in the afternoon: "The lunch effect". Accident Analysis \& Prevention. 2011;43:1104-1116.

24. Meng WL, Shen S, Zhou A. Investigation on fatal accidents in Chinese construction industry between 2004 and 2016. Natural Hazards. 2018;94:655-670.

25. Li R, Pereira FC, Ben-Akiva ME. Overview of traffic incident duration analysis and prediction. European transport research review. 2018;10:113.

26. Lin Y, Li R. Real-time traffic accidents post-impact prediction: Based on crowdsourcing data. Accident Analysis \& Prevention. 2020;145:105696.

27. Al-Najada H, Mahgoub I. Real-time incident clearance time prediction using traffic data from internet of mobility sensors. In Proceedings of 2017 IEEE $15^{\text {th }}$ Intl Conf on Dependable, Autonomic and Secure Computing, $15^{\text {th }}$ Intl Conf on Pervasive Intelligence and Computing, $3^{\text {rd }}$ Intl Conf on Big Data Intelligence and Computing and Cyber Science and Technology Congress (DASC/PiCom/DataCom/CyberSciTech). 2017;728-735.

28. Hojati AT, Ferreira L, Washington S, et al. Hazard based models for freeway traffic incident duration. Accident Analysis \& Prevention. 2013;52:171-181. 
29. Nam D, Mannering F. An exploratory hazard-based analysis of highway incident duration. Transportation Research Part A: Policy and Practice. 2000;34:85-102.

30. Hämäläinen P, Takala J, Saarela KL. Global estimates of fatal work-related diseases. American journal of industrial medicine. 2007;50:28-41.

31. Chiang YH, Wong FKW, Liang S. Fatal construction accidents in Hong Kong. Journal of construction engineering and management. 2018;144:04017121.

32. Glèlè-Ahanhanzo Y, Kpozèhouen A, Paraïso NM, et al. Disability and Related Factors among Road Traffic Accident Victims in Benin: Study from Five Public and Faith-Based Hospitals in Urban and Suburban Areas. Open Journal of Epidemiology. 2018;8:226.

33. Bonnet $\mathrm{E}$, Lechat $\mathrm{L}$, Ridde $\mathrm{V}$. What interventions are required to reduce road traffic injuries in Africa? A scoping review of the literature. PLoS One. 2018;13: 0208195.

34. Moradi A, Nazari SSH, Rahmani K. Sleepiness and the risk of road traffic accidents: A systematic review and meta-analysis of previous studies. Transportation research part F: traffic psychology and behaviour. 2019;65:620-629.

35. Maycock G. Driver sleepiness as a factor in car and HGV accidents. TRL Report. 1995

36. Reissman CJ. Thet alert driver: a trucker's guide to sleep, fatigue, and rest in our 24-hour society. 1996.

37. Heinzmann J, Tate DRD, Scott R. Using technology to eliminate drowsy driving. In Proceedings of SPE International Conference on Health, Safety, and Environment in Oil and Gas Exploration and Production.

38. Connor J, Whitlock G, Norton R, et al. The role of driver sleepiness in car crashes: a systematic review of epidemiological studies. Accident Analysis \& Prevention. 2001;33:31-41.

39. Tregear S, Reston J, Schoelles K, et al. Obstructive sleep apnea and risk of motor vehicle crash: systematic review and meta-analysis. Journal of clinical sleep medicine. 2009;5:573-581.

40. Zhang T, Chan AH. Sleepiness and the risk of road accidents for professional drivers: A systematic review and meta-analysis of retrospective studies. Safety science. 2014;70:180-188.

41. Mansuri FA, Al-Zalabani AH, Zalat MM, Qabshawi RI. Road safety and road traffic accidents in Saudi Arabia: A systematic review of existing evidence. Saudi medical journal. 2015;36:418.

42. Shanks N, Ansari M, Ai-Kalai D. Road traffic accidents in Saudi Arabia. Public health. 1994;108:27-34.

43. Ansari S, Akhdar F, Mandoorah M, et al. Causes and effects of road traffic accidents in Saudi Arabia. Public health. 2000;114:37-39.

44. Jamal A, Rahman MT, Al-Ahmadi HM, et al. The dilemma of road safety in the eastern province of Saudi Arabia: Consequences and prevention strategies. International journal of environmental research and public health. 2020;17:157

45. Vickers NJ. Animal communication: when i'm calling you, will you answer too? Currentbiology. 2017;27:R713-R715.

46. Li DH, Liu Q Yuan W, et al. Relationship between fatigue driving and traffic accident. Journal of traffic and transportation engineering (Xi'an, Shaanxi). 2010;10:104-109.

47. Barrimah I, Midhet F, Sharaf F. Epidemiology of road traffic injuries in Qassim region, Saudi Arabia: consistency of police and health data. International journal of health sciences. 2012;6:31.
48. Almutairi NM, Altamimi MA. The psychosocial consequences of road traffic accidents: a review article. International Journal of Medicine in Developing Countries. 2019;3(12):1104-1109.

49. Gopinath B, Jagnoor J, Harris IA, et al. Prognostic indicators of social outcomes in persons who sustained an injury in a road traffic crash. Injury. 2015;46:909-917.

50. Al-Madani H. Fatal crashes in GCC countries: comparative analysis with EU countries for three decades. Safety and Security Engineering V Rome, Italy. 2013;134:471-482.

51. Airaksinen O, Brox JI, Cedraschi C, et al. European guidelines for the management of chronic nonspecific low back pain. European spine journal. 2006;15:s192.

52. Day S, Dalto J, Fox J, et al. Failure mode and effects analysis as a performance improvement tool in trauma. Journal of Trauma Nursing/ JTN. 2006;13:111-117.

53. Alblowi M, Irfan T, Alshehri K, et al. The prevalence of apathy among road traffic accident survivors. Age. 25;31-58.

54. De Oña J, de Oña R, Eboli L, et al. How to identify the key factors that affect driver perception of accident risk. A comparison between Italian and Spanish driver behavior. Accident Analysis \& Prevention. 2014;73:225235.

55. Al-Tit AA, Ben Dhaou I, Albejaidi FM, et al. Traffic safety factors in the Qassim Region of Saudi Arabia.Sage open. 2020;10:2158244020919500.

56. Al Turki YA. How can Saudi Arabia use the decade of action for road safety to catalyse road traffic injury prevention policy and interventions? International journal of injury control and safety promotion. 2014;21:397402.

57. Gharaibeh ES, Abdo AMA. Assessment of traffic safety and awareness among youth in Al-Ahsa region, Saudi Arabia. Journal of Emerging Trends in Engineering and Applied Sciences. 2011;2:210-215.

58. Al Orf A, Waheed KB, Baig AA, et al. Patterns of injury detected by pan-computed tomography after road traffic accidents: retrospective review from a trauma center in Saudi Arabia. Annals of Saudi medicine. 2018;38:245-250

59. Khan ZU, Al-Asiri KM, Iqbal J. Injury patterns from road traffic accidents. Pakistan Journal of Medical Sciences. 2010;26:394-397.

60. Alkheder S. Learning from the past: traffic safety in the eyes of affected local community in Abu Dhabi City, United Arab Emirates. Transportation letters. 2017;9:20-38.

61. Alshammari MM, El-Fetoh NMA, Alshammari MS, et al. A study on road traffic accidents in Arar, Saudi Arabia. The Egyptian Journal of Surgery. 2017;36:451.

62. Azami-Aghdash S. Meta-synthesis of qualitative evidence in road traffic injury prevention: a scoping review of qualitative studies (2000 to 2019). Archives of public health. 2020;78:1-27.

63. Al-Naami MY, Arafah MA, Al-Ibrahim FS. Trauma care systems in Saudi Arabia: an agenda for action. Annals of Saudi medicine. 2010;30:50-58.

64. Qayed M. Epidemiology of road traffic accidents in Al-Ahssaa Governorate, Saudi Arabia. EMHJ-Eastern Mediterranean Health Journal. 1998;4(3):513-519. 